\title{
Using the Water Drinking Test as an Alternative to Modified Diurnal Tension Curve in Assessment of Short- Term Intraocular Pressure Fluctuation
}

\author{
Tageldin M Othman ${ }^{1 *}$, Aliaa Adly Abas ${ }^{2}$, Ahmed Elbably ${ }^{3}$ and \\ Ahmed Mousa ${ }^{4}$ \\ ${ }^{1}$ Department of Ophthalmology, Faculty of Medicine, Aswan University, Egypt \\ ${ }^{2}$ Aswan Ophthalmology Hospital, Egypt \\ ${ }^{3}$ Locum Glaucoma Consultant, East Kent Hospitals University NHS Foundation, UK. \\ ${ }^{4}$ Nourseen Charity Foundation for Community Ophthalmology, Cairo, Egypt \\ *Corresponding Author: Tageldin M Othman, Department of Ophthalmology, \\ Faculty of Medicine, Aswan University, Egypt.
}

DOI: $10.31080 /$ ASOP.2020.03.0087
Received: January 17, 2020

Published: January 24, 2020

(C) All rights are reserved by Tageldin $\mathbf{M}$

Othman., et al.

\begin{abstract}
Purpose: To assess the relationship between the intraocular pressure (IOP) peaks detected during the water drinking test (WDT) and the modified diurnal tension curve (MDTC) in both normal and glaucomatous eyes.

Basic Procedures: An interventional prospective study that comprised eighty eyes from forty participants. All patients were above 40 years, with primary open-angle glaucoma (POAG) controlled surgically or medically or glaucoma-suspect patients. The control group had normal IOP and a normal examination.

Main Findings: The study included 80 eyes from 40 participants of which 20 (50\%) were males and 20 (50\%) were females. There was a statistically significant difference between the mean mDTC value and the associated WDT peaks among the whole study group $(p=0.003)$, the normal group ( $p=0.041)$ and the glaucoma suspects group $(p<0.0001)$ with no significant difference within the other groups

Principal Conclusions: Intraocular pressure peaks detected during the water-drinking test can be used as a tool to estimate the observed peaks during the modified diurnal tension curve. However, a larger sample may be required to assess whether it is an equivalent alternative measure of IOP fluctuations.
\end{abstract}

Keywords: Water-Drinking Test; Glaucoma; Intraocular Pressure Fluctuation

\section{Introduction}

Glaucoma is a progressive disease affecting the optic nerve and may lead to irreversible visual impairment unless it is properly managed [1]. It is one of the major causes of irreversible low vision and blindness worldwide [2,3]. Meanwhile, increased intraocular pressure (IOP) is one of the major risk factors for glaucoma development. Thus, the designed therapeutic strategies to decrease the IOP remain the main treatment modality to slow down the deterioration in both of the optic nerve head and the associated visual field (VF) [4].

IOP in the human eye is regulated by many factors, including the rate of aqueous humor $(\mathrm{AH})$ production, the facility of trabecular outflow, the rate of fluid drainage through the uveo-scleral outflow pathway, and the pressure in the epi-scleral veins [5]. Moreover, it may vary throughout the 24-hour period due to potential changes in these physiologic parameters [6,7]. The taken measurement of IOP as once time point during office hours may render an incomplete picture of IOP due to the diurnal variation of IOP [8]. Hence, the IOP profile may be better assessed by a 24-hour daily tension curve (DTC) [9]. It is anticipated that the IOP fluctuations and peaks may provide the ophthalmologist with more reliable information about the short-term IOP profile. However, this monitoring may be infeasible and time-consuming either for patients or ophthalmologists; this may turn it into a restricted tool in regular clinical practice. 
The modified diurnal tension curve (MDTC) emerged as an alternative way that involves IOP measurements every 2-3 hours during the daily office hours instead of the 24-hour diurnal tensional curve (DTC) in the habitual position. It is more feasible and may give better information than single IOP measurements [10]. The literature shows that the detected IOP peaks during the DTC may well-correlate with the detected peaks during WDT [11].

The current study addresses the importance of WDT in the assessment of the treatment quality and the potentiality of progression [12]. Water drinking test is done by drinking a considerable volume of water over a relatively short period, with measurements of IOP compared before and after water drinking. The volume of ingested water is either a fixed volume of one liter or using a bodyweight measure, such as $10 \mathrm{ml} / \mathrm{kg}$ of body weight in the duration of 5 minutes, with no fluid ingestion about 2 hours before the test. This will often lead to an elevation of IOP within around 30 minutes [12].

WDT is used to evaluate the ability of the eye to deal with a transient IOP elevation through observing the level of IOP increase and the duration it may take to return to its regular baseline $[12,13]$. The WDT aims to stress the trabecular meshwork (TM) via increasing the episcleral venous pressure (EVP) which takes place secondarily to an increase in central and peripheral venous pressure. This leads to negative transient aqueous [14] that would by its turn, lead to a transient elevation of IOP as a result of the decreased facility outflow from a decreased pressure gradient across the TM [13].

\section{Patients and Methods}

The current study follows an interventional study design that comprised 80 eyes from 40 participants who met the following inclusion criteria; being above 40 years of age, have POAG controlled surgically or medically, or being glaucoma suspects, while the control group had normal IOPs that were confirmed by clinical examination. Patients who have narrow or occludable anterior chamber angle, systemic hypertension, congestive heart failure, chronic renal impairment or having uncontrolled POAG were excluded from the current study.

The final study group was further divided into the medicallycontrolled POAG group (Glaucoma subjects on anti-glaucoma med- ication) and surgically-controlled POAG group (Glaucoma Subjects with SST); patients with Glaucoma-suspects (subjects with suspicious glaucomatous changes that affects the optic disc/ or elevated IOP) and the glaucoma-free group including (healthy non-glaucomatous volunteers). All of the involved patients in this study underwent comprehensive ophthalmic examination including history taking and a complete ophthalmological examination that implied; full anterior segment slit-lamp examination (eyelashes, eyelid margins, palpebral conjunctiva, bulbar conjunctiva, bulbar episclera, sclera, cornea, anterior chamber, iris, lens and anterior vitreous examination where each structure was examined for any abnormality). Anterior chamber angle examination was also conducted including limbal chamber depth technique examination, where the eyes with Van Herick grade I and II were submitted to examination by gonioscopy to exclude the angle-closure glaucoma. Moreover, a fundus examination was conducted to determine any glaucomatous fundal changes and finally, intraocular pressure was assessed.

Each enrolled eye was submitted to a modified diurnal tension curve reading (measurements of intraocular pressure around 9:00 am, 4:00 pm and 9:00 pm by Goldmann's applanation tonometry (HAAG_STREIT international model AT900) and Water drinking test. The evaluation method consisted of a single IOP measurement before intake of one liter of water over five minutes with no previous fluid drinking in the last 2 hours before the test. This step was followed by three times IOP measurements at 30-minute intervals. Both measurements of IOP could be done on the same day, especially in admitted (inpatient ward) patients where the WDT was immediately done following the last reading of mDTC i.e. around 9:00 pm. Meanwhile, others who were not admitted patients were submitted to the mDTC in a clinic visit and WDT in the next followup visit.

\section{Statistical analysis}

Data were collected, stored, cleaned and analyzed using the statistical package for social science (SPSS) version 24 and the following were done: Categorical data were presented as numbers and percentages (No. (\%), while continuous variables were presented as means, standard deviations and ranges (Mean (SD), [min -max]. The comparison between the fluctuations of two methods (mDTC and WDT) was conducted using the Wilcoxon signed-ranked test, and the correlation between peaks and fluctuations was detected by the Spearman correlation test. The confidence interval was set 
Using the Water Drinking Test as an Alternative to Modified Diurnal Tension Curve in Assessment of Short- Term Intraocular Pressure Fluctuation

to $95 \%$ and the margin of error accepted was set to $5 \%$. Any output with a $p$ below 0.05 was interpreted as an indicator of statistical significance.

\section{Results}

The study included 80 eyes from 40 participants of which 20 $(50 \%)$ were females and $20(50 \%)$ were males. The percentage of females exceeded that of males in glaucoma- suspect group $(80 \%$ and $20 \%$, respectively) and the opposite was true for medicallycontrolled glaucoma patients where the percentage of males was exceeding the female percentage ( $75 \%$ and $25 \%$ respectively)., while the other subgroups show relative similar percentages. The mean (SD), range of the recruited participants' age was 48.9 (4.8) years.

The whole study group was further categorized into four subgroups. Fourteen participants (35\%) of the studied sample were confirmed as free from glaucoma (healthy group). Ten participants $(25 \%)$ were suspected to have glaucoma (glaucoma-suspect group) and eight participants (20\%) were previously diagnosed as glaucoma patients that are surgically controlled followed by medical treatment (POAG surgically controlled), while the remaining eight (20\%) didn't have previous surgical intervention (POAG medically controlled). Intraocular measurements by the mDTC showed that the intraocular pressure varied according to the time duration within the day with the highest mean of mDTC IOP readings at 9:00 am. (Table 1). Meanwhile, intraocular measurements by the WDT are demonstrated in (Table 2). Moreover, the highest mean value of WDT IOP readings was detected at 30 minutes. On the other hand, Peak's frequency as regards the day time and WDT readings revealed that the major percentage (95\%) of participants underwent peaks at 9:00 am, while (5\%) at 4:00 pm, zero\% at 9:00 pm (Table 3). In the WDT, the major percentage (92.5\%) of peaks was detected at 30 minutes assessment, while (7.5)\% was detected at the 60 minutes assessment, zero\% at both 90 minutes readings and zero minute readings. There was a statistically significant difference between the mean MDTC value and the associated WDT peaks among the whole study group $(\mathrm{p}=0.003)$, the normal group $(p=0.041)$ and the glaucoma suspects group $(p<0.0001)$ with no significant difference within the other groups (Table 4).

\begin{tabular}{|l|c|c|c|c|c|}
\hline $\begin{array}{l}\text { MDTC Readings } \\
\text { Time }\end{array}$ & $\begin{array}{c}\text { Whole } \\
\text { Sample }\end{array}$ & $\begin{array}{c}\text { POAG Controlled } \\
\text { Medically }\end{array}$ & $\begin{array}{c}\text { POAG Controlled } \\
\text { Surgically }\end{array}$ & $\begin{array}{c}\text { Glaucoma } \\
\text { Suspects }\end{array}$ & $\begin{array}{c}\text { Healthy } \\
\text { Volunteers }\end{array}$ \\
\hline 9am & $17.7 \pm 3.6$ & $16.8 \pm 2.9$ & $15.4 \pm 1.9$ & $22.7 \pm 1.9$ & $15.9 \pm 1.8$ \\
\hline $\mathbf{4 p m}$ & $14.3 \pm 2.1$ & $13.9 \pm 2.2$ & $13.4 \pm 1.7$ & $15.95 \pm 1.9$ & $13.56 \pm 1.9$ \\
\hline $\mathbf{9 p m}$ & $12.21 \pm 1.7$ & $11.9 \pm 1.5$ & $11.5 \pm 1.4$ & $12.8 \pm 1.7$ & $12.4 \pm 1.7$ \\
\hline
\end{tabular}

Table 1: Description of mDTC IOP readings (mean and SD) among different subgroups.

\begin{tabular}{|l|c|c|c|c|c|}
\hline WDT & $\begin{array}{c}\text { Whole } \\
\text { Sample }\end{array}$ & $\begin{array}{c}\text { POAG Controlled } \\
\text { Medically }\end{array}$ & $\begin{array}{c}\text { POAG Controlled } \\
\text { Surgically }\end{array}$ & $\begin{array}{c}\text { Glaucoma } \\
\text { Suspects }\end{array}$ & $\begin{array}{c}\text { Healthy } \\
\text { Volunteers }\end{array}$ \\
\hline Zero time & $12.3 \pm 1.6$ & $12.1 \pm 1.6$ & $11.9 \pm 1.4$ & $12.7 \pm 1.8$ & $12.5 \pm 1.7$ \\
\hline After 30min & $17.03 \pm 2.7$ & $16.9 \pm 2.0$ & $15.6 \pm 1.5$ & $20.5 \pm 2.1$ & $15.5 \pm 1.6$ \\
\hline After 60min & $14.1 \pm 1.7$ & $14.2 \pm 1.9$ & $13.6 \pm 1.6$ & $14.8 \pm 1.9$ & $14.0 \pm 1.6$ \\
\hline After 90min & $12.1 \pm 1.4$ & $12.4 \pm 1.4$ & $11.8 \pm 1.4$ & $12.4 \pm 1.4$ & $12.03 \pm 1.5$ \\
\hline
\end{tabular}

Table 2: Description of WDT readings (mean and SD) among different subgroups. 
Using the Water Drinking Test as an Alternative to Modified Diurnal Tension Curve in Assessment of Short- Term Intraocular Pressure Fluctuation

\begin{tabular}{|l|c|c|c|c|c|}
\hline $\begin{array}{l}\text { WDT Readings } \\
\text { Time }\end{array}$ & $\begin{array}{c}\text { Whole } \\
\text { Sample }\end{array}$ & $\begin{array}{c}\text { POAG Controlled } \\
\text { Medically }\end{array}$ & $\begin{array}{c}\text { POAG Controlled } \\
\text { Surgically }\end{array}$ & $\begin{array}{c}\text { Glaucoma } \\
\text { Suspects }\end{array}$ & $\begin{array}{c}\text { Healthy } \\
\text { Volunteers }\end{array}$ \\
\hline 9am & $76(95 \%)$ & $14(87.5 \%)$ & $16(100 \%)$ & $20(100 \%)$ & $26(92.9 \%)$ \\
\hline $\mathbf{4 p m}$ & $4(5 \%)$ & $2(12.5 \%)$ & $0(0 \%)$ & $0(0 \%)$ & $2(7.1 \%)$ \\
\hline 9pm & $0(0 \%)$ & $0(0 \%)$ & $0(0 \%)$ & $0(0 \%)$ & $0(0 \%)$ \\
\hline
\end{tabular}

Table 3: Frequency and percent of peak IOP measured during (WDT) in relation to time.

\begin{tabular}{|l|c|c|c|}
\hline & MDTC Peak & WDT Peak & P-Value \\
\hline Whole Study Group & $17.6(3.5)$ & $17.04(2.8)$ & 0.003 \\
\hline $\begin{array}{l}\text { POAG controlled } \\
\text { medically }\end{array}$ & $17.2 \pm 2.6$ & $17.2 \pm 1.9$ & 0.718 \\
\hline $\begin{array}{l}\text { POAG controlled } \\
\text { surgically }\end{array}$ & $15.4 \pm 1.9$ & $15.6 \pm 1.5$ & 0.291 \\
\hline Glaucoma suspects & $19.1 \pm 1.97$ & $20.5 \pm 2.1$ & $<0.0001$ \\
\hline Healthy volunteers & $16.1 \pm 1.8$ & $15.8 \pm 1.4$ & 0.041 \\
\hline
\end{tabular}

Table 4: Difference between mDTC peaks and WDT peaks.

Assessment of the range of IOP fluctuation in the mDTC showed that the Intraocular pressure fluctuation range varied based on the type of subgroups. For instance, it ranged from $(2-6 \mathrm{mmHg})$ in $96.5 \%$ among the healthy group, while it ranged (5 -13 $\mathrm{mmHg}$ ) in $90 \%$ of the glaucoma suspect group. In the surgically controlled

glaucoma group, the fluctuation showed a range of (2 - $6 \mathrm{mmHg}$ ) at the same levels among the healthy group. The fluctuation range among the on-medication glaucoma subgroup (3 - $8 \mathrm{mmHg}$ ) was varied to occupy the area from normal group levels to glaucoma suspect group levels (Table 5). There were relatively similar results in the WDT fluctuations, as IOP fluctuation ranged from (3-7 $\mathrm{mmHg}$ ) in $96.4 \%$ among the healthy group, while it ranged (5-11 $\mathrm{mmHg}$ ) in $85 \%$ of the glaucoma suspect group. In the surgically controlled glaucoma group and on-medication glaucoma subgroup, the fluctuation showed the same range of fluctuation $(3-6 \mathrm{mmHg}$ ) (Table 6). Additionally, 77 (96.3\%) eyes showed a difference of $\leq$ $2 \mathrm{mmHg}$ between the two methods. Meanwhile, no significant difference was detected between the mean value of MDTC and WDT fluctuations at glaucoma controlled medically subgroup, but there were significant differences between the mean of mDTC and WDT fluctuations in other groups ( $\mathrm{p}<0.001)$ (Table 7).

\begin{tabular}{|l|c|c|c|c|c|}
\hline $\begin{array}{l}\text { Fluctuation of IOP } \\
\text { (MMHG) }\end{array}$ & $\begin{array}{c}\text { Whole } \\
\text { Sample }\end{array}$ & $\begin{array}{c}\text { POAG Controlled } \\
\text { Medically }\end{array}$ & $\begin{array}{c}\text { POAG Controlled } \\
\text { Surgically }\end{array}$ & $\begin{array}{c}\text { Glaucoma } \\
\text { Suspects }\end{array}$ & $\begin{array}{c}\text { Healthy } \\
\text { Volunteers }\end{array}$ \\
\hline & No (\%) & No (\%) & No (\%) & No (\%) & No(\%) \\
\hline 2 & $2(2.5 \%)$ & $0(0 \%)$ & $2(12.5 \%)$ & $0(0 \%)$ & $(\%)$ \\
\hline 3 & $20(25 \%)$ & $1(6.3 \%)$ & $4(25 \%)$ & $0(0 \%)$ & $15(53.6 \%)$ \\
\hline 4 & $15(18.8 \%)$ & $0(0 \%)$ & $4(25 \%)$ & $0(0 \%)$ & $11(39.3 \%)$ \\
\hline 5 & $14(17.5 \%)$ & $7(43.8 \%)$ & $5(31.3 \%)$ & $1(5 \%)$ & $1(3.6 \%)$ \\
\hline 6 & $6(7.5 \%)$ & $4(25 \%)$ & $1(6.3 \%)$ & $0(0 \%)$ & $1(3.6 \%)$ \\
\hline 7 & $2(2.5 \%)$ & $2(12.5 \%)$ & $0(0 \%)$ & $0(0 \%)$ & $0(0 \%)$ \\
\hline 8 & $7(8.8 \%)$ & $2(12.5 \%)$ & $0(0 \%)$ & $5(25 \%)$ & $0(0 \%)$ \\
\hline 9 & $1(1.3 \%)$ & $0(0 \%)$ & $0(0 \%)$ & $1(5 \%)$ & $0(0 \%)$ \\
\hline 10 & $4(5 \%)$ & $0(0 \%)$ & $0(0 \%)$ & $4(10 \%)$ & $0(0 \%)$ \\
\hline 11 & $6(7.5 \%)$ & $0(0 \%)$ & $0(0 \%)$ & $6(30 \%)$ & $0(0 \%)$ \\
\hline 12 & $1(1.3 \%)$ & $0(0 \%)$ & $0(0 \%)$ & $1(5 \%)$ & $0(0 \%)$ \\
\hline 13 & $2(2.5 \%)$ & $0(0 \%)$ & $0(0 \%)$ & $2(10 \%)$ & $0(0 \%)$ \\
\hline Range & $2-13$ & $3-8$ & $2-6$ & $5-13$ & $2-6$ \\
\hline
\end{tabular}

Table 5: The range of mDTC fluctuation in the different subgroups. 
Using the Water Drinking Test as an Alternative to Modified Diurnal Tension Curve in Assessment of Short- Term Intraocular Pressure Fluctuation

\begin{tabular}{|l|c|c|c|c|c|}
\hline $\begin{array}{l}\text { Fluctuation Of } \\
\text { IOP (MMHG) }\end{array}$ & $\begin{array}{c}\text { Whole } \\
\text { Sample }\end{array}$ & $\begin{array}{c}\text { POAG Controlled } \\
\text { Medically }\end{array}$ & $\begin{array}{c}\text { POAG Controlled } \\
\text { Surgically }\end{array}$ & $\begin{array}{c}\text { Glaucoma } \\
\text { Suspects }\end{array}$ & Healthy Volunteers \\
\hline & No (\%) & No (\%) & No (\%) & No (\%) & No (\%) \\
\hline $\mathbf{3}$ & $7(8.8 \%)$ & $4(25 \%)$ & $4(25 \%)$ & $0(0 \%)$ & $2(7.1 \%)$ \\
\hline $\mathbf{4}$ & $22(27.5 \%)$ & $7(43.8 \%)$ & $7(43.8 \%)$ & $0(0 \%)$ & $14(50 \%)$ \\
\hline $\mathbf{5}$ & $20(25 \%)$ & $3(18.8 \%)$ & $3(18.8 \%)$ & $1(5 \%)$ & $11(39.3 \%)$ \\
\hline $\mathbf{6}$ & $9(11.3 \%)$ & $2(12.5 \%)$ & $2(12.5 \%)$ & $2(10 \%)$ & $0(0 \%)$ \\
\hline $\mathbf{7}$ & $6(7.5 \%)$ & $0(0 \%)$ & $0(0 \%)$ & $3(15 \%)$ & $1(3.6 \%)$ \\
\hline $\mathbf{8}$ & $6(7.5 \%)$ & $0(0 \%)$ & $0(0 \%)$ & $4(20 \%)$ & $0(0 \%)$ \\
\hline $\mathbf{9}$ & $4(5 \%)$ & $0(0 \%)$ & $0(0 \%)$ & $4(20 \%)$ & $0(0 \%)$ \\
\hline $\mathbf{1 0}$ & $3(3.8 \%)$ & $0(0 \%)$ & $0(0 \%)$ & $3(15 \%)$ & $0(0 \%)$ \\
\hline $\mathbf{1 1}$ & $3(3.8 \%)$ & $0(0 \%)$ & $0(0 \%)$ & $3(15 \%)$ & $0(0 \%)$ \\
\hline Range & $3-11$ & $3-6$ & $3-6$ & $5-11$ & $3-7$ \\
\hline
\end{tabular}

Table 6: The range of fluctuation in WDT in different subgroups.

\begin{tabular}{|l|c|c|c|c|}
\hline & $\begin{array}{c}\text { MDTC fluctuation } \\
\text { Mean } \pm \mathbf{S D}(\mathbf{m m H g})\end{array}$ & $\begin{array}{c}\text { WDT fluctuation } \\
\text { Mean } \pm \mathbf{S D}(\mathbf{m m H g})\end{array}$ & T & p-value \\
\hline POAG controlled medically & $5.8 \pm 1.3$ & $2.1 \pm 0.34$ & -0.775 & 0.451 \\
\hline POAG controlled surgically & $3.9 \pm 1.2$ & $4.2 \pm 0.98$ & 11.067 & $<0.001^{*}$ \\
\hline Glaucoma suspects & $9.9 \pm 1.97$ & $8.5 \pm 1.8$ & -5.347 & $<0.001^{*}$ \\
\hline Healthy volunteers & $3.6 \pm 0.74$ & $4.4 \pm 0.79$ & 5.659 & $<0.001^{*}$ \\
\hline
\end{tabular}

Table 7: Comparison between IOP fluctuation by mDTC and WDT for each subgroup separately.

\section{Discussion}

Glaucoma is known to be a progressive disease of the optic nerve that may lead to an irreversible impairment of visual acuity unless it is properly treated [1]. The measurement IOP is essential in the diagnosis and treatment of OAG, but a single measurement in the ophthalmologist's clinic may or may not reflect the changes in IOP during day or night [15]. The process of 24 Hrs IOP monitoring may be unpractical and time-consuming for both physicians and patients, which may turn it into a restricted tool in clinical practice. Alternatively, the modified diurnal tension curve (mDTC) provides summarized information of the 24-h DTC which is important in managing glaucoma patients [10].

The WDT method was first described as a diagnostic tool for glaucoma where a 6 - $8 \mathrm{mmHg}$ increase in IOP was considered as a threshold to confirm the diagnosis. Although WDT may not be an ideal confirmatory test for glaucoma diagnosis (because of a large number of the reported false positive and false negative cases), it may reflect IOP peaks and fluctuations [16].
In our study, we attempted to compare both peaks and fluctuations of IOP collected from the modified diurnal tension curve that were collected from WDT in various subtypes.

Our results show that the highest mean of mDTC IOP readings was during the morning. These findings did not agree with the reported results of some other similar studies such as Liu., et al. study that worked on 16 volunteer and provided evidence that the mean IOP was statistically significantly more increased in the late nocturnal period than in the regular diurnal/wake period for both the sitting and the supine IOPs [6]. Meanwhile, the WDT readings demonstrated that the highest mean (peak) of WDT readings was at the 30 minutes readings. This fact was similar to the findings of Yi-Chieh Poon., et al. study. There was a significant increase in IOP that persisted up to 30 minutes after water ingestion in the POAG [17], and this also agree with study of Nongpiur ME., et al. which demonstrated that a significant increase in IOP at 30 minutes after the WDT and decrease in serum osmolality [18]. Moreover, water intake was also found to be associated with an increase in 
blood pressure and peripheral vascular resistance [6]. Therefore, changes in hemodynamics may be associated with an increased episcleral venous pressure, which leads by its turn to a decreased outflow facility.

The majority (95\%) of patients underwent peaks at 9:00 am which agrees with Shaoying Tan., et al. study that included 22 POAG patients (22 eyes), and including primary angle-closure glaucoma PACG (31 eyes). Tan's study proved that the mean patientmeasured IOP at the regular home environment was at its highest level at 08:00 am, which tended to drop over the day course, and reached its lowest value around midnight, in both of the PACG and POAG eyes in this reported study [19].

Regarding the WDT, the major percentage (92.5\%) of peaks was at 30 minutes readings. Thus, it is not impossible to rely on the first two readings in clinical practice/assessment when their time is insufficient to complete the whole test. Meanwhile, the WDT peaks were significantly correlated with the mDTC peaks in most groups besides that, there was no statistically significant difference in the Wilcoxon test between the mean value of mDTC and the WDT peaks. Findings from our study agree with the findings by Kumar and colleagues when 25 patients were enrolled in this study, and proved that the detected IOP peak that is measured during diurnal testing showed strong correlation with peak IOP during WDT, whereas the mean IOP peak measured through diurnal testing, was of no statistical difference with that measured by WDT. However, the study recommended enrolling a larger sample to develop concrete evidence [11].

Each subgroup of our sample has its specific pattern in terms of the range of IOP fluctuation of Mdtc. The glaucoma group with SST has a specific range of fluctuation $(2-6 \mathrm{mmHg})$ which was similar to the normal subgroup range $(2-6 \mathrm{mmHg})$. Both groups showed a range less than that of glaucoma on medications $(3-8 \mathrm{mmHg}$ ), while the glaucoma suspect subgroup showed the highest range of IOP fluctuation (5-13 mmHg). These findings are similar to the results of Yassein HA., et al. which included 40 participants (40 eyes) showed the glaucoma with SST subgroup has a specific fluctuation range of (1.5 - $5 \mathrm{mmHg})$ that was similar to normal subgroup range (1-5 $\mathrm{mmHg}$ ) where both of them demonstrated a lower range than that of the on-medication glaucoma group (4-11 mmHg) [20].

The water-drinking test fluctuations showed poor correlation between the mean of mDTC and WDT fluctuations, in most of the subgroups as there was a significant difference in the Wilcoxon test which agrees with Kumar., et al. study that showed poor cor- relation [11]. Nevertheless, the study of Yassein HA., et al. showed that the water drinking test fluctuations were significantly correlated with the mDTC fluctuations $[20,21]$.

Additionally, there were no detected peaks in the 90 minutes IOP reading of WDT which made it impossible to compare the mDTC fluctuation with the rising volume of the IOP during the first 60 minutes of WDT to reduce the time required to do the test. That yielded a statistically significant correlation between the 0-60 minutes IOP rise and the mDTC fluctuations in most groups. Therefore, we can use this "modified" water-drinking test in clinical practice when our time is restricted.

The current study suffers some limitations such as the relatively small sample size and the need for assessing other glaucoma indices to enrich the analysis and evaluate the severity of IOP increase. However, it can be concluded that: The detected intraocular pressure peaks during the water-drinking test may be used in practice to estimate the peaks observed during the modified diurnal tension curve. However, a larger sample is required to assess whether it is an equivalent alternative measure of IOP fluctuations. Further studies with a higher sample size in clinical trial study design are highly recommended for developing more concrete evidence on these findings.

\section{Funding}

This research did not receive any specific grant from funding agencies in the public, commercial, or not-for-profit sectors.

\section{Bibliography}

1. Chauhan BC and SM Drance. "The Relationship between Intraocular Pressure and Visual Field Progression in Glaucoma”. Graefe's Archive for Clinical and Experimental Ophthalmology 230.6 (1992): 521-526.

2. Cook C and P Foster. "Epidemiology of Glaucoma: What's New?" Canadian Journal of Ophthalmology 47.3 (2012): 223226.

3. Resnikoff S., et al. "Global Data on Visual Impairment in the Year 2002". Bulletin of the World Health Organization 82.11 (2004): 844-851.

4. Mansouri K and R Weinreb. "Continuous 24-Hour Intraocular Pressure Monitoring for Glaucoma--Time for a Paradigm Change". Swiss Medical Weekly 142 (2012): w13545.

5. Yang H., et al. "3-D Histomorphometry of the Normal and Early Glaucomatous Monkey Optic Nerve Head: Lamina Cribrosa and Peripapillary Scleral Position and Thickness". Investigative Ophthalmology and Visual Science 48.10 (2007): 4597-607. 
6. Liu JH., et al. "Nocturnal Elevation of Intraocular Pressure Is Detectable in the Sitting Position". Investigative Ophthalmology and Visual Science 44.10 (2003): 4439-4442.

7. Loewen NA., et al. "Increased 24-Hour Variation of Human Intraocular Pressure with Short Axial Length". Investigative Ophthalmology and Visual Science 51.2 (2010): 933-937.

8. Barkana Y., et al. "Clinical Utility of Intraocular Pressure Monitoring Outside of Normal Office Hours in Patients with Glaucoma”. Arch Ophthalmol 124.6 (2006): 793-797.

9. Asrani S., et al. "Large Diurnal Fluctuations in Intraocular Pressure Are an Independent Risk Factor in Patients with Glaucoma". Journal of Glaucoma 9.2 (2000): 134-142.

10. Vasconcelos-Moraes CG and R Susanna. "Correlation between the Water Drinking Test and Modified Diurnal Tension Curve in Untreated Glaucomatous Eyes". Clinics (Sao Paulo) 63.4 (2008): 433-436.

11. Kumar RS., et al. "Does Peak Intraocular Pressure Measured by Water Drinking Test Reflect Peak Circadian Levels? A Pilot Study". Clinical and Experimental Ophthalmology 36.4 (2008): 312-315.

12. Goldberg I and CI Clement. "The Water Drinking Test". American Journal of Ophthalmology 150.4 (2010): 447-449.

13. De Moraes CG., et al. "Choroidal Expansion During the Water Drinking Test". Graefe's Archive for Clinical and Experimental Ophthalmology 247.3 (2009): 385-389.

14. Susanna R., et al. "Correlation of Asymmetric Glaucomatous Visual Field Damage and Water-Drinking Test Response". Investigative Ophthalmology and Visual Science 47.2 (2006): 641-644.

15. Wilensky JT. "The Role of Diurnal Pressure Measurements in the Management of Open Angle Glaucoma". Current Opinion in Ophthalmology 15.2 (2004): 90-92.

16. Roth JA. "Inadequate Diagnostic Value of the Water-Drinking Test". British Journal of Ophthalmology 58.1 (1974): 55-61.

17. Poon YC., et al. "Intraocular Pressure Fluctuation after Water Drinking Test in Primary Angle-Closure Glaucoma and Primary Open-Angle Glaucoma”. Indian Journal of Ophthalmology 64.12 (2016): 919-923.

18. Nongpiur ME., et al. "Evaluation of Choroidal Thickness, Intraocular Pressure, and Serum Osmolality after the Water Drinking Test in Eyes with Primary Angle Closure". Investigative Ophthalmology and Visual Science 56.4 (2015): 2135-2143.
19. Tan S., et al. "Comparison of Self-Measured Diurnal Intraocular Pressure Profiles Using Rebound Tonometry between Primary Angle Closure Glaucoma and Primary Open Angle Glaucoma Patients". PLoS One 12.3 (2017): e0173905.

20. Yassein HA., et al. "The Value of Water Drinking Test as a Clue for Short Term Intraocular Pressure Fluctuation". Journal of Clinical and Experimental Ophthalmology 7:2 7 (2016): 2.

21. Lu CC., et al. "Water Ingestion as Prophylaxis against Syncope". Circulation 108.21 (2003): 2660-2665.

\section{Assets from publication with us}

- Prompt Acknowledgement after receiving the article

- Thorough Double blinded peer review

- Rapid Publication

- Issue of Publication Certificate

- High visibility of your Published work

Website: https://www.actascientific.com/

Submit Article: https://www.actascientific.com/submission.php Email us: editor@actascientific.com

Contact us: +919182824667 